\section{О.Ю.Потоцкая ${ }^{1}$ А.С.Лапсарь ${ }^{2}$}

${ }^{1}$ ГУ «Днепропетровская медицинская академия МЗ Украины»

${ }^{2}$ КУ «Запорожское областное патологоанатомическое бюpo» $30 \mathrm{C}$

Ключевые слова: лимфатические узлы, гемальные узлы, лимфоциты, дендритные клетки, макрофаги, интранодальные сосуды.

Надійшла: 16.04.2017

Прийнята: 27.05.2017
DOI: https://doi.org/10.26641/1997-9665.2017.2.28-34

УДК [611.42+612.1]:611.018

\section{ОСОБЕННОСТИ КЛЕТОЧНОГО СОСТАВА И МИКРОАРХИТЕКТУРЫ ГЕМАЛЬНЫХ УЗЛОВ ЧЕЛОВЕКА}

Исследование выполнено в рамках научно-исследовательской работы «Нормальный и аномальный морфогенез компонентов сердечно-сосудистой системы человека и экспериментальных животных» (номер государственной регистраичи 0114U005592).

Реферат. Клеточный состав лимфатических узлов хорошо описан, в то время как в гемальных узлах он все еще плохо изучен. Цель исследования - определить особенности распределения основных типов иммунокомпетентных клеток и стромальных элементов в гемальных узлах человека. В качестве материала были использованы гемальные узлы, которые были взяты во время вскрытия у пациентов, умерших вследствие сердечно-сосудистой или респираторной патологии. Стандартные гистологические и иммуногистохимические методы были использованы. Распределение лимфоцитов исследовали с помощью антител против CD20, CD3 и CD8. Для анализа дендритных клеток и макрофагов использовали антитела к S100 и CD68. Стромальные элементы были обнаружены с помощью антител к SMA и CD34. Выводы: гемальные узлы имеют тот же характер клеточного распределения, что и лимфатические узлы, за исключением Вклеток, которые одинаково присутствуют в паракортексе и медуллярных тяжах. Среди хорошо развитой интранодальной сосудистой системы были обнаружены сосуды, выстланые CD34-негативными клетками.

Morphologia. - 2017. - T. 11, № 2. - C. 28-34.

(C) О.Ю.Потоцкая, А.С.Лапсарь, 2017

$\triangle$ Pototskaya.o.yu@gmail.com

Pototskaya O.Yu., Lapsar A.S. Peculiarities of cellular composition and microarchitecture of human hemal nodes.

ABSTRACT. Background. Cellular composition of lymph nodes is well described while in hemal nodes it is still poorly investigated. Objective. To define peculiarities of distribution of major types of immunocompetent cells and stromal elements in human hemal nodes. Methods. Hemal nodes were taken during autopsy from patients who died due to cardiovascular or respiratory pathology. Standard histological and immunohistochemical methods were used to detect different cellular types and stromal elements. Results. Distributions of lymphocytes was investigated with the help of anti-CD20, CD3 and CD8 antibodies. To analyze dendritic cells and macrophages anti S100 and CD68 antibodies were used. Stromal elements were detected with the help of anti SMA and CD34 antibodies. Conclusion. Hemal nodes have the same character of immune cells' distribution as in lymph nodes, except B-cells, which are equally present in paracortex and medullary cords. Among well-developed intranodal vasculature there were revealed CD34-negatve vessels, which are also known in literature as system of conduits.

Key words: lymph nodes, hemal nodes, lymphocytes, dendritic cells, macrophages, intranodal vessels.

\title{
Citation:
}

Pototskaya OYu, Lapsar AS. [Peculiarities of cellular composition and microarchitecture of human hemal nodes]. Morphologia. 2017;11(2):28-34. Russian.

\section{Введение}

На основании распределения основных видов лимфоцитов в структуре лимфатических узлов (ЛУ) выделяют корковое вещество, где преобладают В-лимфоциты, паракортекс, в котором преобладают Т-лимфоциты, а также мозговое вещество, представленное смесью разных видов лимфоцитов [1]. Миграцией лейкоцитов в направлении конкретной зоны управляют стромальные элементы - фибробластические ретику- лярные клетки [2]. Распределение клеток в пределах гемальных узлов (ГУ) изучено намного меньше по сравнению с лимфатическими узлами. Иммуногистохимическое исследование мезентериальных гемальных узлов овцы не выявило кардинальных отличий в количестве основных подтипов лимфоцитов по сравнению с лимфоузлами той же группы [3]; к похожим выводам пришли ученые, исследовавшие височные гемальные и лимфатические узлы быка [4]. В то же 
время при изучении гемальных узлов телят было обнаружено, что они содержат больше $\mathrm{CD}^{+}$и $\gamma \delta$ Т-лимфоцитов по сравнению с лимфатическими узлами [5]. Гемальные узлы человека остаются мало изученными, в том числе с точки зрения их клеточного состава, поэтому вопросы их функции и роли в иммунной системе и организме в целом остаются до сих пор открытыми.

Цель: определить особенности распределения основных типов иммунокомпетентных клеток, а также элементов стромы в гемальных узлах человека.

\section{Материалы и методы}

Материалом для исследования послужили мезентериальные гемальные узлы умерших вследствие соматических заболеваний (инфаркт миокарда, расслоение и разрыв аорты) людей. Материал, полученный во время аутопсии, фиксировали в нейтральном забуференном формалине, обезвоживали в спиртах возрастающей концентрации и заливали в парафин. Для изучения гистологического строения гемальных узлов на светооптическом уровне срезы толщиной 5-7 мкм окрашивали гематоксилином-эозином в соответствии с общепринятой методикой.

Детекцию аутофлуоресценции гранул липофусцина проводили при помощи микроскопа Primo Star (ZEISS, Германия) в ультрафиолетовом спектре возбуждения 390 нм (FITC) и камеры ToupCam UCMOS03100KPA.

Для иммуногистохимического исследования срезы 7 мкм толщиной помещались на адгезивные стекла. После депарафинизации и регидратации проводили демаскировку антигена путем автоклавирования срезов в фосфатном буфере $\mathrm{pH}=6,0$ на протяжении 10 мин при температуре $90^{\circ} \mathrm{C}$. Для дальнейшей обработки срезов использовалась система визуализации LSAB2 System, HRP (биотинилированные антитела и пероксидазный комплекс, Dako, Дания) и DAB хромоген. Блокирование эндогенной пероксидазы осуществляли $3 \%$ раствором перекиси водорода (пероксидазный блок из набора).

Инкубацию с первичными антителами производили на протяжении 30-60 мин при комнатной температуре. Были использованы первичные антитела mouse anti-human CD20 (1/250); rabbit anti-human CD3 (1/150); rabbit anti-human CD8 (1/50); mouse anti-human CD68 (1/100); mouse anti-human S100 (1/100); rabbit anti-human $\alpha$-SMA (1/100); mouse anti-human CD34 (1/200); все антитела производства Thermo Fisher Scientific (США). Согласно протоколу после промывания срезов от неконъюгированных антител Biotinylated Link, Streptavidin-HRР и SubstrateChromogen Solution были последовательно использованы. До покрытия срезов стеклом их дополнительно докрашивали гематоксилином Майера. Анализ экспрессии маркеров проводили по коричневому цвету.

\section{Результаты}

Для решения поставленной задачи по изучению особенностей клеточного состава гемальных узлов человека нами было проведено иммуногистохимическое исследование с использованием маркеров основных иммунокомпетентных клеток и стромальных элементов. Ниже приведено описание распределения в тканях гемальных узлов позитивно окрашенных клеточных элементов в отдельности по каждому маркеру.

\section{CD20 (маркер В-лимфоччитов)}

CD20-позитивные клетки формировали лимфоидные фолликулы коры гемальных узлов, в которых изредка обнаруживались светлые реактивные центры (рис.1, А). Как таковая паракортикальная зона, как правило, обедненная Влимфоцитами по сравнению с остальными регионами лимфатических узлов, содержала такое же количество $\mathrm{CD} 20+$ клеток, как и мозговые тяжи. В синусах гемальных узлов (в том числе и субкапсулярном), обнаруживались немногочисленные CD20+ клетки, в то время как в венулах с высоким эндотелием они выявлялись очень редко.

\section{CD3 (маркер T-лимфочитов)}

CD3-позитивные клетки распределялись равномерно во всех зонах ГУ за исключением лимфоидных фолликулов, в составе которых они были немногочисленны (рис. 1, В). В светлых реактивных центрах вторичных фолликулов количество CD3+ клеток было выше, чем в первичных фолликулах, вероятно, они представляли собой группу фолликулярных хелперов. В некоторых участках коры гемальных узлов лимфоидные узелки отсутствовали; количество и распределение CD3+ клеток в них было таким же, как и в мозговых тяжах узла. Количество Тлимфоцитов в синусах было значительно меньше, чем в лимфоидной ткани; существенных отличий в их количестве клеток между субкапсулярным и воротным синусом не наблюдалось. В венулах с высоким эндотелием также выявлялись единичные CD3+ клетки.

CD8 (маркер T-лимфочитов-киллеров)

Характер распределения $\mathrm{CD}^{+}$клеток совпадал с паттерном распределения $\mathrm{CD}^{+}$клеток (рис. 1, C), особенно многочисленными эти клетки были вдоль стенок некоторых венул с высоким эндотелием. Количество Т-киллеров в мозговых синусах было выше, чем в субкапсулярном.

$\alpha-S M A$ (маркер гладкомымечных клеток)

Иммуногистохимическое окрашивание срезов ГУ выявило $\alpha-\mathrm{SMA}^{+}$клетки в составе оболочки сосудов, а также в капсуле узла. Во внутренней структуре узлов ГМК располагались по периметру лимфоидной ткани, а также формировали строму паракортикальной зоны и мозговых тяжей (рис. 1, D). В составе фолликулов коркового вещества $\alpha-\mathrm{SMA}^{+}$клетки отсутствовали. 

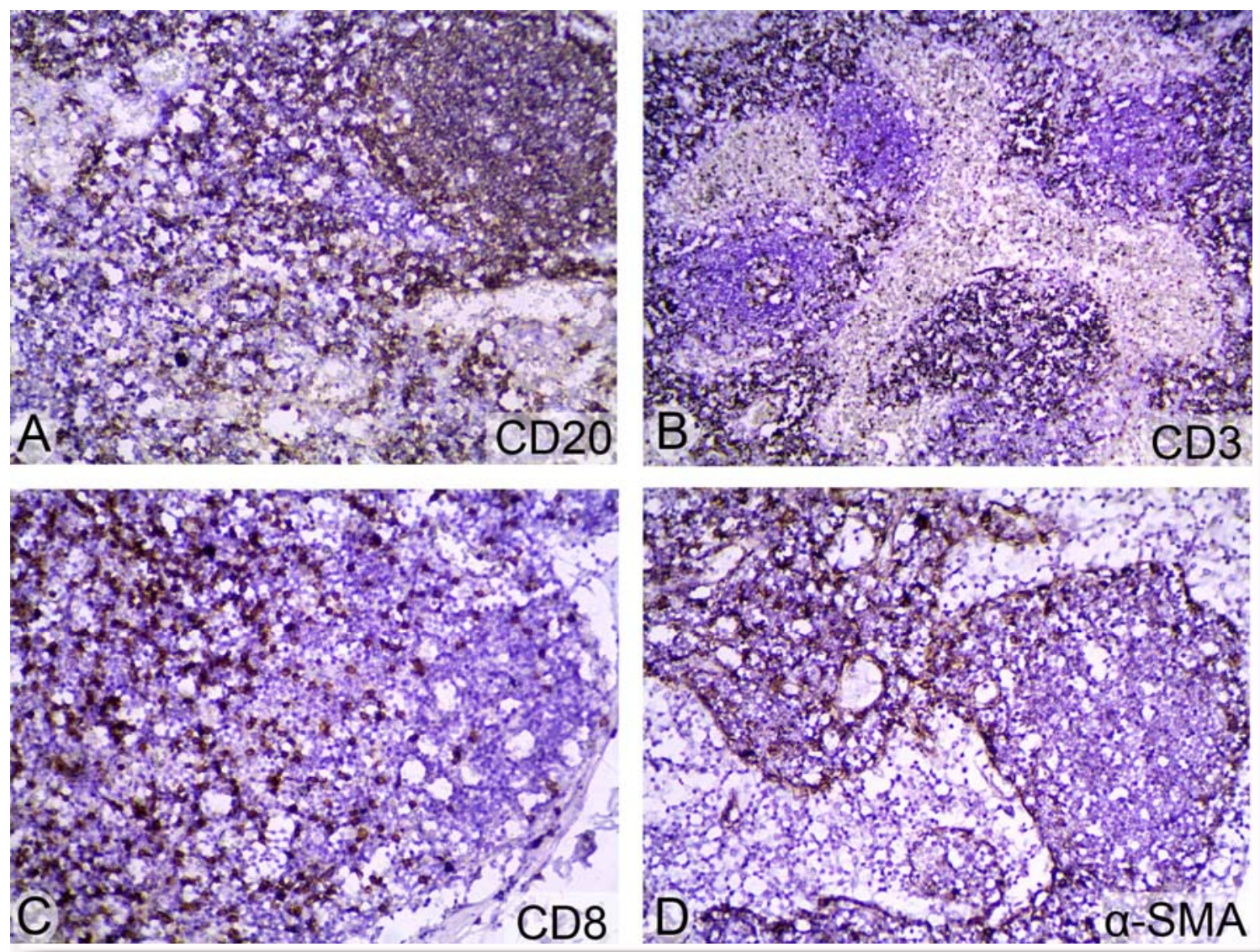

Рис. 1. Распределение основных типов лимфоцитов в ткани мезентериальных ГУ человека.

A - иммуногистохимическая реакция с антителами к CD20 - маркером В-лимфоцитов;

B - иммуногистохимическая реакция с антителами к CD3 - маркером Т-лимфоцитов;

C - иммуногистохимическая реакция с антителами к CD8 - маркером Т-киллеров;

D - иммуногистохимическая реакция с антителами к с а-SMA - маркером гладкомышечных клеток стромы. ×100.

CD68 (маркер макрофагов)

Основное количество $\mathrm{CD}_{68}^{+}$клеток было равномерно распределено между синусами гемальных узлов, где они представляли довольно гетерогенную группу клеток (рис. 2, А). Отличия в строении касались диаметра клеток (он варьировал от 5 до 20 мкм), формы клеток (округлая, отростчатая, кольцевая), а также наличия гранул в цитоплазме (рис. 2, В).

Крупные $\mathrm{CD}^{+} 8^{+}$клетки часто приобретали форму кольца, в центре которого располагались эритроциты, что свидетельствует об их активном участии в эритрофагоцитозе. Также в цитоплазме некоторых из этих клеток наблюдались очертания одного или нескольких эритроцитов. Свидетельством хронического эритрофагоцитоза в гемальных узлах является наличие крупных клеток (около 20 мкм), цитоплазма которых заполнена гранулами липофусцина, который хорошо выявляется благодаря своей способности к аутофлуоресценции (рис. 2, С). Можно предположить, что по мере фагоцитирования эритроцитов макрофаги постепенно увеличиваются в размере, накапливают липофусцин (непереваренные остатки мембран, подвергшиеся перекисному окисле- нию) и лишаются ядра.

В лимфоидной ткани гемальных узлов $\mathrm{CD} 68^{+}$клетки выявлялись в небольшом количестве, как в мозговых тяжах, так и в фолликулах коркового вещества. Размеры клеток были меньше по сравнению с такими же в синусах, также их отличие состояло в более отростчатой форме и отсутствии признаков эритрофагоцитоза.

S100 (маркер дендритных клеток, ДК)

Общее количество $\mathrm{S} 100^{+}$клеток в гемальных узлах было намного меньше по сравнению с $\mathrm{CD}^{+} 8^{+}$клетками; большая часть из них располагалась в составе лимфоидной ткани. В пределах синусов $\mathrm{S}_{100^{+}}$распределялись равномерно, в то время как в лимфоидной ткани они располагались группами (рис. 2, D), как правило, в парафолликулярных зонах, хотя в самих фолликулах они отсутствовали. По внешним характеристикам $\mathrm{S} 100^{+}$можно было разделить на 2 группы: округлые, лимфоцитоподобные, около 6 мкм; и более крупные, отростчатые, до 15 мкм. В цитоплазме клеток обоих типов гранулы или эритроциты выявлялись крайне редко (рис. 2, Е, стрелки), что свидетельствует об их незначительном участии в элиминации красных кровяных клеток. 


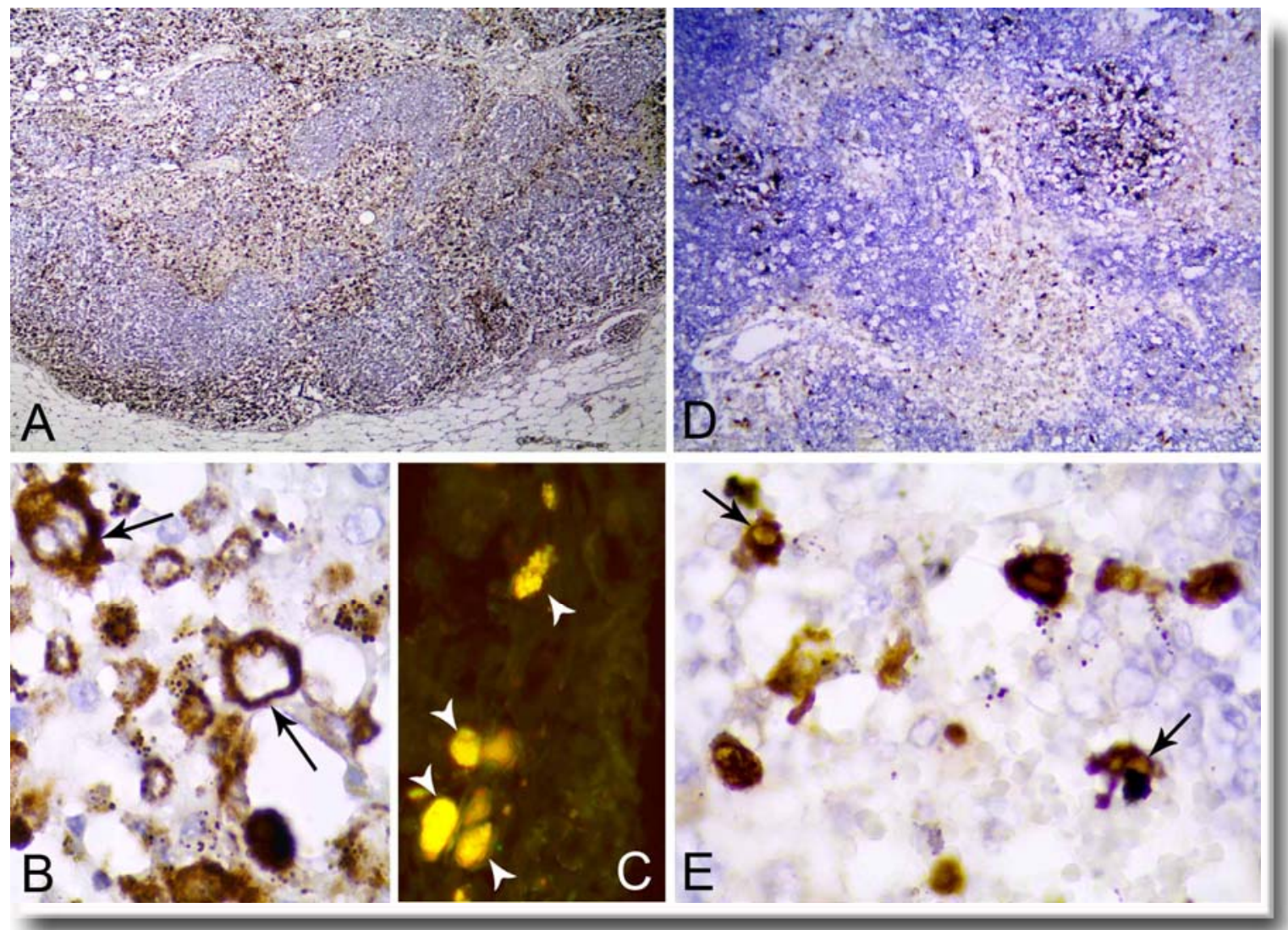

Рис. 2. Распределение макрофагов и дендритных клеток в ткани мезентериальных ГУ человека. А, В - иммуногистохимическая реакция с антителами к CD68 - маркером макрофрагов; стрелки на В указывают на клетки кольцеобразной формы, свидетельствующие об эффероцитозе. С - аутофлуоресценция гранул липофусцина внутри макрофагов (клеток морской синевы) в ультрафиолетовом спектре. D-E - иммуногистохимическая реакция с антителами к S100 маркером дендритных клеток; стрелки на E указывают на позитивно окрашенные клетки с эритроцитами в цитоплазме. A, D - ×100; B, E - ×1000; C - ×400.

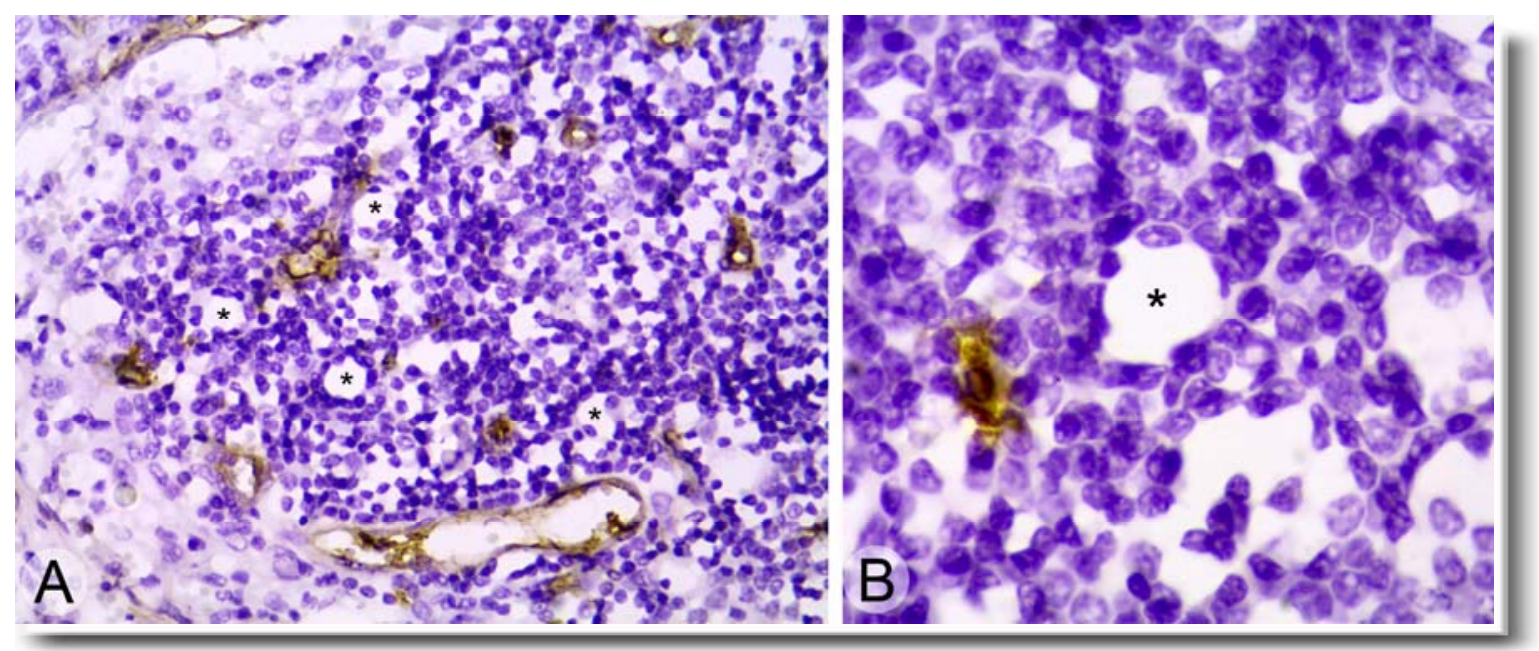

Рис. 3. Сосуды гемальных узлов. А-B - иммуногистохимическая реакция с антителами к CD34. Звездочками обозначены сосуды, выстланные CD34-клетками. А - ×200; В - ×1000.

CD34 (маркер эндотелия кровеносных сосу-
дов)
Обработка препаратов гемальных узлов ан-
тителами к CD34 (рис. 3) выявила развитую сосудистую сеть внутри лимфоидной ткани узла с большим количеством капилляров 5-7 мкм в диаметре. В мозговых тяжах и паракортикальной зоне наблюдалось наибольшее количество сосудов, в то время как в фолликулах (особенно первичных) их было значительно меньше. Наряду с 
выстланными эндотелием сосудами в лимфоидной ткани гемальных узлов обнаруживалась разветвленная сеть каналов, в которых отсутствовала выстилка из CD34-позитивных клеток и эритроциты (рис. 3). В среднем диаметр таких каналов варьировал от 10 до 20 мкм, их количество было несколько ниже в составе лимфоидных фолликулов.

\section{Обсуждение}

Распределение лимфоцитов

Общие принципы распределения лимфоцитов в ГУ сходны с таковыми в ЛУ. Основное отличие состоит в относительно равномерном распределении CD20 клеток в паракортикальной зоне (где в ЛУ их количество существенно ниже) и мозговом веществе узла. Подобные наблюдения были сделаны при исследовании ГУ овцы [3], в то время как при изучении мезентериальных ГУ быка отличий в распределении В-клеток от ЛУ выявлено не было [5].

Структура сосудистого русла гемальных узлов

Дополнительной особенностью строения ГУ является наличие развитой системы каналов, которые выстланы CD34- клетками эндотелия (спецификация макрера CD34+ включает клетки эндотелия кровеносных, но не лимфатических сосудов, за исключением опухолевых тканей [6]). По своему описанию эта система сходна с описанным в литературе лабиринтом полостей, ограниченных эпителиоидным монослоем фибробластических ретикулярных клеток, заякоренных во внеклеточный матрикс - подобие базальной мембраны [7]. Авторы, описавшие эту сеть в коре ЛУ, предполагают, что она облегчает амебоидное движение лейкоцитов внутри ЛУ, а также регулирует движение жидкости. Также в литературе имеются сведения о наличии внутри ЛУ интранодальных лимфатических сосудов, развитие которых ассоциировано с опухолевым ростом и метастазированием [8].

Существуют данные об участии макрофагов в лимфангиогенезе: они могут сами встраиваться в стенку новообразованных сосудов, или стимулировать деление предсуществующих клеток эндотелия $[9,10]$. По некоторым данным наличие опухоль-ассоциированных нейтрофилов в лимфоузлах способствует метастазированию за счет стимуляции лимфангиогенеза, хотя прямая связь между этими событиями не продемонстрирована, но выявлена корреляция между уровнем нейтрофилов и количеством интранодальных лимфатических сосудов [11]. Интересно, что в наших исследованиях также наблюдается взаимосвязь между наличием в ГУ нейтрофилов и сети каналов, сходных с лимфатическими капиллярами, но существует ли между этими явлениями прямая связь еще предстоит выяснить.

$\alpha$-SMA-позитивные клетки стромы гемальных узлов
Строма паракортекса и межфолликулярных участков ЛУ образована фибробластическими ретикулярными клетками (ФРК), которые определяются благодаря наличию в них экспрессии PDPN, $\alpha$-SMA и отсутствию CD31 [12]. Стромальные клетки составляют $\sim 1 \%$ от общего количества клеток ЛУ и обеспечивают не только механическую опору, но также вырабатывают ряд факторов, необходимых для поддержания жизнеспособности наивных CD4+ и CD8+ Tлимфоцитов, ангиогенеза и хемоаттракции лейкоцитов [13]: анализ транскриптома ФРК ЛУ показал наличие в них экспрессии IL-7, VEGF-A, VEGF-C, CXCL13, CCL19, CCL21a, а также мышечного белка десмина [14]. Кроме паракринной регуляции иммунных реакций ФРК принимают участие в презентации антигенов при помощи МHC II, экспрессия которого усиливается при воспалении [14]. ФРК в паракортикальной зоне ЛУ эктопически экспрессируют и презентуют периферические тканевые антигены наивным Тклеткам, стимулируя их к пролиферации [15]. Этот механизм обеспечивает выработку периферической толерантности к собственным антигенам кишечника [16]. В нашем исследовании распределение $\alpha$-SMA+ клеток в гемальных узлах не отличалось от описанного для лимфатических узлов человека.

Распределение макрофагов и дендритных
клеток

Маркер S100 часто используется в качестве маркера дендритных клеток [17], а также Шванновских клеток, астроцитов, эпендимоцитов, меланомы и ее метастазов, точнее клеток нейрального происхождения $[18,19]$. В этом аспекте особенно интересны результаты исследования нейроиммунных взаимодействий в лимфатических узлах крысы: выяснилось, что нервные окончания, которые коэпспрессируют норэпинефрин, вазоактивный интестинальный полипептид и нейропептид $\mathrm{Y}$, избирательно контактируют с S100+ клетками [20]. Другая группа исследователей использовала замороженные образцы тканей ЛУ крысы и продемонстрировала связь ДК с афферентными нервными окончаниями, предполагая возможность их воздействия на нервную систему [21]. Подобные исследования дополнительно подчеркивают важность изучения нормального распределения ДК в ЛУ. В классических исследованиях было продемонстрировано увеличения представительства S- $100^{+}$клеток в паракортикальной зоне ЛУ при лимфадените [17], в то время как паттерн распределения этих клеток в ЛУ при нормальных условиях четко не охарактеризован. Другие исследования дополнительно продемонстрировали гетерогенность состава дендритных клеток ЛУ [22], а также отличия в распределении ДК и МФ в пределах зон ЛУ [17], что совпадает с нашими данными о морфологических отличиях в пределах группы 
$\mathrm{S} 100^{+}$клеток, а также о разнице в их количестве и распределении по сравнению с $\mathrm{CD} 68^{+}$клетками (см. рис. 2 А и D).

CD68 относится к гликопротеинам, ассоциированным с лизосомами, и в основном используется в качестве маркера макрофагов [23]. Большое количество $\mathrm{CD}^{+} 8^{+}$клеток в ГУ обусловлено их участием в эритрофагоцитозе, что также отмечено многими авторами при изучении гемальных, гемолимфатических узлов, а также при исследовании лимфатических узлов после пересадки в них селезенки [24-26]. Последующее преобразование некоторых макрофагов, участвующих в эритрофагоцитозе, в гистиоциты морской синевы было описано нами ранее [27]; в данной работе было получено дополнительное подтверждение накопления в таких клетках липофусцина за счет его аутофлуоресценции.

\section{Выводы}

1. Распределение основных типов иммунокомпетентных клеток в гемальных узлах в целом соответствует паттерну лимфатических узлов, за исключением $\mathrm{CD} 20^{+}$-клеток (В-лимфоцитов), которые равномерно распределяются в паракортикальной зоне и мозговых тяжах.

2. В структуре гемальных узлов наряду с кровеносными сосудами присутствует развитая сеть каналов, выстланная CD34-негативными клетками, которая в литературе описана как интранодальные лимфатические сосуды / система кондуитов.

Перспективы дальнейших исследований состоят в исследовании динамики клеточного состава гемальных узлов человека при различных заболеваниях печени и кишечника.

\section{Литературные источники References}

1. Willard-Mack CL. Normal structure, function, and histology of lymph nodes. Toxicol Pathol. 2006;34(5):409-24.

2. Bajénoff M, Egen JG, Koo LY, Laugier JP, Brau F, Glaichenhaus N, Germain RN. Stromal cell networks regulate lymphocyte entry, migration, and territoriality in lymph nodes. Immunity. 2006;25(6):989-1001. doi: 10.1016/j.immuni.2006.10.011

3. Thorp BH, Seneque S, Staute K, Kimpton WG. Characterization and distribution of lymphocyte subsets in sheep hemal nodes. Dev Comp Immunol. 1991;15(4):393-400.

4. Casteleyn CR, Breugelmans S, Simoens P, Van den Broeck W. Morphological and immunological characteristics of the bovine temporal lymph node and hemal node. Vet Immunol Immunopathol. 2008;126(3-4):339-50.

doi: 10.1016/j.vetimm.2008.09.010.

5. Zhang W, Nasu T, Hosaka YZ, Yasuda M. Comparative studies on the distribution and population of immunocompetent cells in bovine hemal node, lymph node and spleen. J Vet Med Sci. 2012;74(4):405-11.

6. Fiedler U, Christian S, Koidl S, Kerjaschki D, Emmett MS, Bates DO, Christofori G, Augustin HG. The sialomucin CD34 is a marker of lymphatic endothelial cells in human tumors. Am J Pathol. 2006;168(3):1045-53. doi: 10.2353/ajpath.2006.050554

7. Kaldjian EP, Gretz JE, Anderson AO, Shi Y, Shaw S. Spatial and molecular organization of lymph node $\mathrm{T}$ cell cortex: a labyrinthine cavity bounded by an epithelium-like monolayer of fibroblastic reticular cells anchored to basement membrane-like extracellular matrix. Int Immunol. 2001;13(10):1243-53.
8. Ji RC. Lymph node lymphangiogenesis, a new concept for modulating tumor metastasis and inflammatory process. Histol Histopathol. 2009;24(3):377-84. doi: 10.14670/HH-24.377.

9. Cursiefen C, Chen L, Borges LP, Jackson D, Cao J, Radziejewski C, D'Amore PA, Dana MR, Wiegand SJ, Streilein JW. VEGF-A stimulates lymphangiogenesis and hemangiogenesis in inflammatory neovascularization via macrophage recruitment. J Clin Invest. 2004;113(7):1040-50. doi: 10.1172/ JCI20465

10. Kerjaschki D. The crucial role of macrophages in lymphangiogenesis. J Clin Invest. 2005;115(9):2316-9.

11. Tokumoto M, Tanaka H, Ohira M, Go Y, Okita Y, Sakurai K, Toyokawa T, Kubo N, Muguruma K, Maeda K, Sawada T, Hirakawa K. A positive correlation between neutrophils in regional lymph nodes and progression of gastric cancer. Anticancer Res. 2014;34(12):7129-36.

12. Chai Q, Onder L, Scandella E, Gil-Cruz C, Perez-Shibayama C, Cupovic J, Danuser R, Sparwasser T, Luther SA, Thiel V, Rülicke T, Stein JV, Hehlgans T, Ludewig B. Maturation of lymph node fibroblastic reticular cells from myofibroblastic precursors is critical for antiviral immunity. Immunity. 2013;38(5):1013-24.

doi: 10.1016/j.immuni.2013.03.012.

13. Link A, Vogt TK, Favre S, Britschgi MR, Acha-Orbea H, Hinz B, Cyster JG, Luther SA. Fibroblastic reticular cells in lymph nodes regulate the homeostasis of naive $\mathrm{T}$ cells. Nat Immunol. 2007;8(11):1255-65.

14. Malhotra D, Fletcher AL, Astarita J, Lukacs-Kornek V, Tayalia P, Gonzalez SF, Elpek KG, Chang SK, Knoblich K, Hemler ME, Brenner MB, Carroll MC, Mooney DJ, Turley SJ; Immunological 
Genome Project Consortium. Transcriptional profiling of stroma from inflamed and resting lymph nodes defines immunological hallmarks. Nat Immunol. 2012;13(5):499-510. doi: 10.1038/ni.2262.

15. Fletcher AL, Lukacs-Kornek V, Reynoso ED, Pinner SE, Bellemare-Pelletier A, Curry MS, Collier AR, Boyd RL, Turley SJ. Lymph node fibroblastic reticular cells directly present peripheral tissue antigen under steady-state and inflammatory conditions. J Exp Med. 2010;207(4):689-97. doi: 10.1084/jem.20092642.

16. Lee JW, Epardaud M, Sun J, Becker JE, Cheng AC, Yonekura AR, Heath JK, Turley SJ. Peripheral antigen display by lymph node stroma promotes $\mathrm{T}$ cell tolerance to intestinal self. Nat Immunol. 2007;8(2):181-90.

17. Takahashi K, Yamaguchi H, Ishizeki J, Nakajima T, Nakazato Y. Immunohistochemical and immunoelectron microscopic localization of S-100 protein in the interdigitating reticulum cells of the human lymph node. Virchows Arch B Cell Pathol Incl Mol Pathol. 1981;37(2):125-35.

18. Moore BW. A soluble protein characteristic of the nervous system. Biochem Biophys Res Commun. 1965;19(6):739-44.

19. Dabbs DJ, editor. Diagnostic immunohistochemistry: theranostic and genomic applications. 3rd ed. Saunders Elsevier; 2010.960 p.

20. Huang J, Zhu C, Zhang P, Zhu Q, Liu Y, Zhu Z, Wang M, Li W, Yang G, Dong N, Liu J, Chen L, Zhang Y, Yang R, Deng L, Fan J, Wang X,
Liu J, Ma B, Fu Q, Wu K. S100+ cells: a new neuroimmune cross-talkers in lymph organs. Sci Rep. 2013;3:1114. doi: 10.1038/srep01114.

21. Wülfing C, Günther HS. Dendritic cells and macrophages neurally hard-wired in the lymph node. Sci Rep. 2015;5:16866. doi:10.1038/srep16866

22. Takahashi K, Asagoe K, Zaishun J, Yanai H, Yoshino T, Hayashi K, Akagi T. Heterogeneity of dendritic cells in human superficial lymph node: in vitro maturation of immature dendritic cells into mature or activated interdigitating reticulum cells. Am J Pathol. 1998;153(3):745-55. doi: 10.1016/ S0002-9440(10)65618-0

23. Holness CL, Simmons DL. Molecular cloning of CD68, a human macrophage marker related to lysosomal glycoproteins. Blood. 1993;81(6):160713.

24. Ezeasor DN, Singh A, Sims DE. Erythrophagocytosis in the caprine hemal node. Acta Anat (Basel). 1989;134(4):341-5.

25. Sasaki K. Erythrophagocytosis of the lymph node macrophages caused by autotransplantation of the splenic tissue into the lymph nodes of rat. Anat Anz. 1990;171(5):335-42.

26. Cerutti P, Guerrero F. Erythropoiesis and erythrophagocytosis in bovine haemal nodes. International Journal of Morphology. 2008;26(3):557.

27. Pototska OYu, Lapsar HS. [Peculiarities of human pancreatolienal hemolymph node structure and cellular composition]. Morphologia. 2016;10(1):77-86. Russian.

\section{Потоцька О.Ю., Лапсарь Г.С. Особливості клітинного складу та мікроархітектури гемальних вузлів людини.}

Реферат. Клітинний склад лімфатичних вузлів добре описаний, в той час як в гемальних вузлах він все ще погано вивчений. Мета дослідження - визначити особливості розподілу основних типів імунокомпетентних клітин і стромальних елементів в гемальних вузлах людини. Як матеріал були використані гемальні вузли, які були взяті під час розтину пацієнтів, померлих внаслідок серцево-судинної або респіраторної патології. Стандартні гістологічні та імуногістохімічні методи були використані. Розподіл лімфоцитів досліджували за допомогою антитіл проти CD20, CD3 і CD8. Для аналізу дендритних клітин і макрофагів використовували антитіла до S100 і CD68. Стромальні елементи були виявлені за допомогою антитіл до SMA і CD34. Висновки: гемальні вузли мають той же характер клітинного розподілу, що і лімфатичні вузли, за винятком В-клітин, які однаково присутні в паракортексі і мозкових тяжах. Серед добре розвиненої інтранодальної судинної системи були виявлені судини, вислані CD34-негативними клітинами.

Ключові слова: лімфатичні вузли, гемальні вузли, лімфоцити, дендритні клітини, макрофаги, інтранодальні судини. 